\title{
Análise exploratória sobre as causas da redução da informalidade no Brasil na década de 2000
}

\begin{abstract}
Resumo
O objetivo deste trabalho é analisar os possíveis fatores da redução da informalidade no Brasil na década de 2000. Os possíveis fatores estão agrupados em quatro categorias: regulação estatal e as suas mudanças, escolaridade dos trabalhadores, crescimento econômico e mudanças estruturais. Os resultados indicam uma possível explicação da queda da informalidade no nível de escolaridade, nas mudanças estruturais e, em parte, nas modificações na regulação estatal e na tributação. $\mathrm{O}$ crescimento econômico parece não ter um papel importante no fenômeno estudado.
\end{abstract}

Palavras-chave: Informalidade; Crescimento; Educação; Regulação estatal

Classificação JEL: O17; I25

\begin{abstract}
The aim of this paper is to analyze the possible factors of informality reduction in Brazil in the decade of 2000. The possible factors are grouped in four categories: public regulation and its changes, schooling of workers, economic growth, and structural changes. The results suggest a hypothetical explanation of informality reduction in the level of schooling, in the structural changes and, in part, in the changes of public regulation and taxation. Economic growth appears not to have an important role.
\end{abstract}

Key words: Informality; Growth, Education; Public regulation

JEL classification: $\mathrm{O} 17 ; \mathrm{I} 25$ 


\section{INTRODUÇÃO}

O presente trabalho investiga um fenômeno novo no passado recente da economia brasileira: a redução da informalidade.

Enquanto os anos de 1980 e 1990 foram caracterizados por um crescimento do trabalho informal de forma consistente, na década de 2000 assistimos ao processo inverso. A queda do nível de informalidade no Brasil na década de 2000 pode ser vista como um aspecto interessante no contexto econômico do país. Como podemos ver na Tabela 1, a proporção de ocupados na informalidade passou de 55,1\% em 2001 para 48,7\% em 2009, com uma queda de 6,4 pontos percentuais. A queda é mais relevante se consideramos o período anterior (1992-2001) onde esta proporção aumentou ou foi constante dependendo do ano considerado.

Tabela 1. Proporção de ocupados informais (\%)

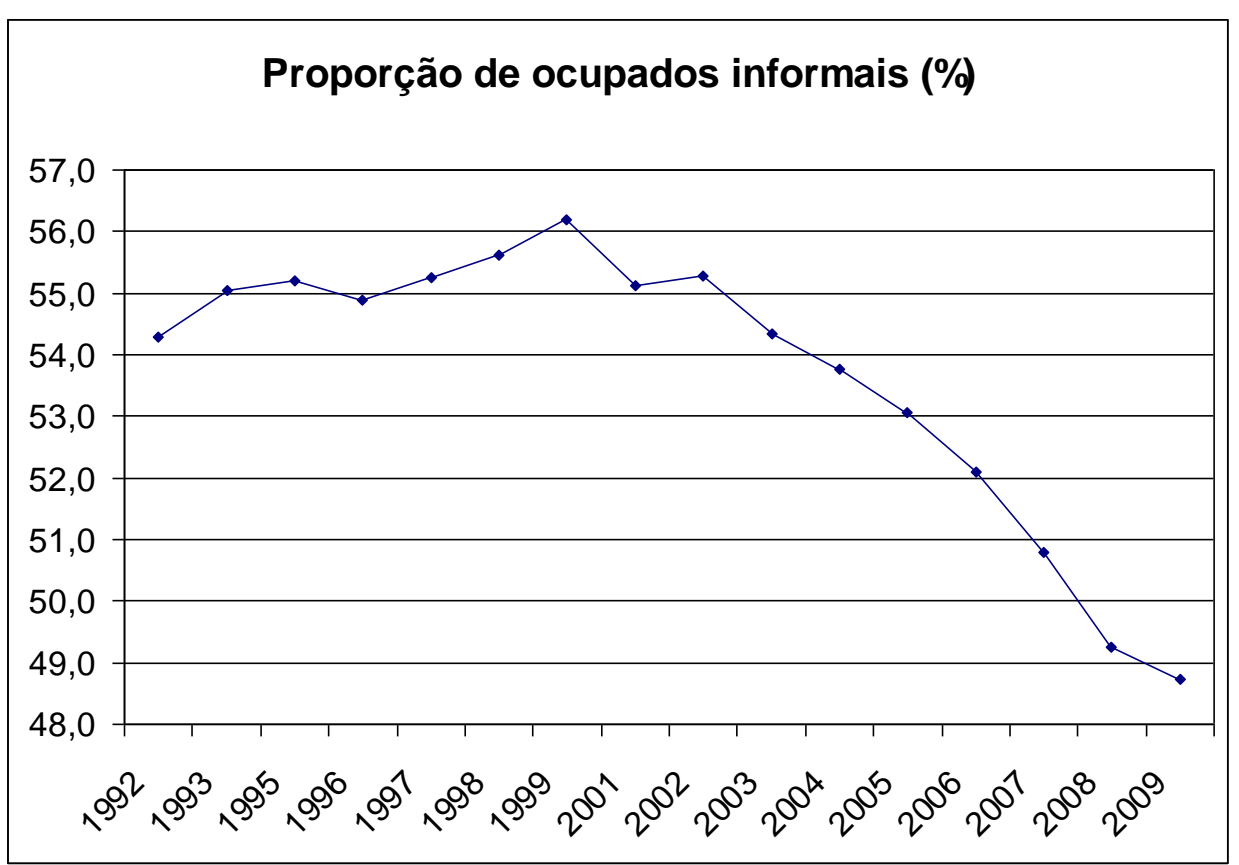

Fonte: IPEA, 2011

Uma das características da literatura relativa à informalidade é a enorme multiplicidade de definições de setor informal utilizadas tanto em pesquisas teóricas quanto empíricas. No Brasil, essa dificuldade 
foi em grande parte reduzida pelo fato de a legislação exigir que todos os trabalhadores que recebem um salário possuam uma carteira de trabalho assinada, o que fez com que a definição de informalidade ficasse largamente associada à detenção ou não da mesma (Ulyssea, 2006).

O trabalho informal é um fenômeno econômico importante a ser investigado porque tem vários efeitos na economia como um todo. A informalidade cria problemas na arrecadação de recursos financeiros do estado, porque impostos sobre este trabalho não são recolhidos. A larga presença desta tipologia de trabalho gera também problemas de acesso ao crédito pelas empresas. Não podemos também esquecer que a informalidade é ligada na maioria das vezes a falta de proteção dos trabalhadores no momento do serviço, mas também, no futuro, considerada a falta de pagamentos ao sistema da previdência social. Mais ainda, a informalidade cria ineficiência na escolha de políticas públicas por parte do estado, porque os dados dos trabalhadores informais não fazem parte das estatísticas oficiais. A literatura sobre o tema põe em evidencia outros problemas da informalidade: falta de eficiência econômica e competição predatória entre os setores formal e informal da economia. De fato, uma consequência negativa da informalidade seria a disseminação de distorções e ineficiências resultado de comportamentos rent-seeking e a introdução de incertezas sobre a condição fiscal futura. Além disso os economistas consideram necessário o combate à informalidade na tentativa de busca de maior equidade distributiva tanto na taxação como na oferta de serviços públicos e de proteção social (Neri, 2007).

Considerada a relevância do problema, o presente trabalho tem o objetivo de investigar os possíveis fatores da recente queda do trabalho informal, ou seja, quais fatores determinam a informalidade no longo prazo e, em consequência, a capacidade do estado de reduzi-la através políticas públicas.

O artigo é constituído de quatro seções.

A primeira seção evidencia os aspectos da teoria econômica ligados à informalidade e também algumas características da recente formalização no Brasil que podem ser relevantes.

A segunda seção é um resumo das principais evidências empíricas, destacando os fatos que podem servir para desenvolver a pesquisa deste artigo.

A terceira seção é uma descrição do modelo de análise empírica desenvolvida sobre o tópico através os instrumentos econométricos, no qual cada possível causa é medida na sua influência sobre a informalidade.

A quarta seção apresenta os resultados das estimativas e, finalmente, a última seção conclui. 


\section{O processo de formalização - uma visão geral}

\subsection{Aspectos Teóricos}

O setor informal de uma economia pode ser influenciado positivamente ou negativamente por vários fatores. A teoria econômica e vários estudos sobre o tópico podem evidenciar os fatores mais importantes a ser analisado neste trabalho.

Este artigo divide os possíveis fatores que influenciam em quatro categorias:

1. nível de escolaridade dos indivíduos que entram no mercado do trabalho;

2. mudanças na regulação estatal e na tributação;

3. crescimento econômico;

4. mudanças estruturais.

Variações na escolaridade podem ser consideradas como um primeiro fator que hipoteticamente explica as mudanças no setor informal de um país.

Respeito ao nível de educação formal dos trabalhadores sem carteira de trabalho assinada, existe um consenso, nas pesquisas desenvolvidas no Brasil, de que estes apresentam, em média, menos anos de estudo do que os trabalhadores formais.

As evidências apresentadas pela literatura internacional indicam que o retorno à escolaridade é maior no setor formal do que no informal (Ulyssea, 2006). Existe então um incentivo ao aumentar o nível de estudos para que os trabalhadores transitem do setor informal para o formal. Considerando o fato que o mercado de trabalho brasileiro é segmentado entre setor formal e informal, podemos supor que o meio para transitar da informalidade para trabalhos formais seja aumentar o nível de estudos.

Os programas de assistência escolar, algum dos quais são considerados na análise empírica deste trabalho, podem ser vistos como um índice do grau de investimento na educação. Os programas de assistência escolar têm em geral quatro objetivos, não necessariamente na ordem de importância: i) aumentar a escolaridade e assim garantir uma renda estável no longo prazo; ii) reduzir a pobreza no curto prazo; iii) reduzir o nível de trabalho infantil; e iv) atuar como uma espécie de rede de 
seguridade. No contexto deste trabalho ressaltam-se o primeiro e o terceiro objetivos. O primeiro é direto: conforme as crianças se tornam mais educadas, suas chances futuras no mercado de trabalho serão melhores, assim como seus salários, e irão escolher mais provavelmente a formalidade. $\mathrm{O}$ terceiro objetivo não é direto, pois não aparece nas finalidades dos programas. De fato, não existe a exigência que os responsáveis se comprometam diretamente a retirar a criança do trabalho. Porém, considerando que a criança obrigatoriamente terá seu tempo livre reduzido com a presença na escola, podemos supor que ela naturalmente deixará o mercado de trabalho (Kassouf et al., 2004). Podemos afirmar que o primeiro objetivo tem influência sobre o trabalho informal no longo prazo, em vez o terceiro no curto prazo.

O segundo fator que pode explicar as variações na informalidade está ligado à regulação pública e à presença de tributos elevados.

Os efeitos dos níveis de alíquotas sobre arrecadação tributária são descritos através a Curva de Laffer. Em geral a teoria econômica representa a curva de Laffer como uma curva em forma de sino. O conceito que está atrás desta curva é que quanto maior a alíquota, menor a base de arrecadação de impostos. A informalidade também é influenciada por encargos fiscais crescentes. De fato, o nível de tributos é um dos fatores que um empresário considera quando ele escolhe se for formal ou informal. Podemos supor a existência de uma relação de causalidade entre nível de tributos e grau de informalidade, isto é, o aumento de alíquotas observado leva a um aumento da informalidade nas relações das empresas com o estado, o que leva a novos aumentos das alíquotas. Vem se criando assim um círculo vicioso que pode ser bloqueado somente com uma mudança nas políticas do governo (Neri, 2007).

Sobre a regulação do estado, podemos evidenciar o fato que uma redução na burocracia leva a uma maior facilidade de entrada e permanência de uma empresa no setor formal.

Um terceiro possível fator pode ser o crescimento econômico.

Pode-se notar como o ciclo econômico influencia o setor informal. A firma tem duas vias para reagir a um choque adverso utilizando a sua demanda de trabalho: demissão de parte de seus trabalhadores ou redução de salários num mercado desregulamentado. Quando a lei não permite aos empregadores reduzir salários, eles vão mudar os níveis de emprego. Considerando que o setor formal da economia é menos flexível respeito a ajustes salariais, muitos economistas supõem um comportamento anticíclico das taxas de informalidade (Mello e Santos, 2009).

Um último fator que pode mudar o nível de informalidade pode ser uma mudança estrutural.

De fato, a retração de um setor caracterizado por um grau de informalidade elevado (o setor de agricultura e de serviços) e a expansão de um setor mais intensivo em postos de trabalho formais (o setor industrial), são suficientes para gerar um significativo efeito que, por si só, tenderia a elevar o 
grau de formalidade no mercado de trabalho. Uma mudança estrutural deste tipo na composição setorial, mas no sentido inverso, explica $25 \%$ do aumento no grau de informalidade observado ao longo da década de 90 (Ulyssea, 2006).

\subsection{Algumas características da formalização brasileira}

Como já observamos no Brasil tive uma queda da proporção de ocupados na informalidade de 6,4 pontos percentuais, de 55,1\% em 2001 para 48,7\% em 2009.

A diminuição da informalidade brasileira foi maior nas regiões não metropolitanas (NRMs) do que nas regiões metropolitanas (RMs) (tabela 2). A principal característica que explica a diferença do grau entre as RMs e as NRMs é o maior nível de informalidade nas NRMs e não a diferente composição das atividades econômicas (Barbosa Filho, De Moura, 2012).

Tabela 2. Taxa de informalidade nas regiões metropolitana e não metropolitana (\%)

\begin{tabular}{|l|l|l|}
\hline & $\begin{array}{l}\text { Região Metropolitana } \\
(\%)\end{array}$ & $\begin{array}{l}\text { Região Não- } \\
\text { Metropolitana (\%) }\end{array}$ \\
\hline 2002 & 35,6 & 48,1 \\
\hline 2003 & 34,0 & 46,8 \\
\hline 2004 & 34,4 & 46,8 \\
\hline 2005 & 33,8 & 45,5 \\
\hline 2006 & 33,1 & 44,9 \\
\hline 2007 & 31,7 & 43,2 \\
\hline 2008 & 31,2 & 41,9 \\
\hline 2009 & 29,7 & 41,6 \\
\hline
\end{tabular}

Fonte: Barbosa Filho, De Moura, 2012

Na tabela 3 podemos observar a taxa de informalidade da economia brasileira juntamente com a taxa de desemprego. A princípio, os dados sugerem que existe uma correlação entre desemprego e grau de informalidade, supondo que as novas vagas de trabalho criadas no período 2002-2008 tinham um papel importante na formalização do mercado de trabalho. 
No entanto, nota-se que a taxa de informalidade continuou a diminuir mesmo durante a crise de 2009, diferentemente do que aconteceu com a taxa de desemprego, que subiu repentinamente. $\mathrm{O}$ fato indica que fatores distintos podem explicar o nível das duas variáveis consideradas (Barbosa Filho, De Moura, 2012).

Tabela 3. Taxa de desemprego e taxa de informalidade

\begin{tabular}{|l|l|l|}
\hline & Taxa de desemprego (\%) & Taxa de Informalidade (\%) \\
\hline 2002 & 9,1 & 43,6 \\
\hline 2003 & 9,7 & 42,3 \\
\hline 2004 & 8,9 & 42,5 \\
\hline 2005 & 9,3 & 41,4 \\
\hline 2006 & 8,4 & 40,7 \\
\hline 2007 & 8,2 & 39,1 \\
\hline 2008 & 7,1 & 38,1 \\
\hline 2009 & 8,3 & 37,4 \\
\hline
\end{tabular}

Fonte: Barbosa Filho, De Moura, 2012

\section{Revisão da literatura}

Na recente literatura econômica, o trabalho de Mello e Santos (2009) sobre a queda recente da informalidade no Brasil se destaca entre os outros. Os autores verificam que os níveis de escolaridade estão, em qualquer instante de tempo, entre as principais características individuais que determinam a pertinência de trabalhadores a um dos dois setores da economia considerados (formal e informal). A conclusão do trabalho de Mello e Santos (2009) é que a melhoria na distribuição de educação da população total é o verdadeiro responsável pelo aumento no grau de formalização da economia no Brasil. Comparando a distribuição educacional dos ocupados, os autores observam que essa pode variar tanto porque a distribuição de educação na população sofre alterações ao longo do tempo, quanto porque as chances de que pessoas com um dado nível educacional estejam ocupadas mudam com o passar dos anos.

Um argumento proposto em muitos trabalhos anteriores, entre os quais o mais conhecido é Barros e Corseuil (2001), ressalta a importância de choques institucionais que mudam a relação entre o lucro da produção formal e o da informal, afetando em consequência a fração da mão-de-obra alocada no 
setor informal. Podemos usar a Constituição Federal, promulgada em 1988, como exemplo desse tipo de inovação, a qual inseriu novos custos no trabalho e estimulou assim a substituição de trabalhadores formais por informais, possivelmente contribuindo para o crescimento do setor informal nos anos 1990 (Mello, Santos, 2009).

Contudo, o trabalho de Barros e Corseuil (2001) não fornece nenhuma evidência de que a mudança constitucional tivesse qualquer efeito sobre os parâmetros de demanda de trabalho. No entanto, este trabalho revela consideráveis flutuações temporais dos coeficientes, fato que poderia ser explicado por eventos macroeconômicos. Mesmo quando as variáveis macroeconômicas são tidas em conta, ainda os autores não encontraram nenhuma evidência de que a Constituição de 1988 teve qualquer efeito sobre a demanda por trabalho.

Outras causas de mudança no tamanho da informalidade usada em vários artigos (Bosh et al 2007 e Carneiro, 1997) são choques agregados, os quais são transmitidos de modo distinto aos setores formal e informal da economia. De fato, estes trabalhos evidenciam um comportamento pro-cíclico da formalização. Porém, Bosh et al. (2007) afirmam que as transições entre os setores, formal e informal, são pró-cíclicas. Os autores fornecem fortes evidências de que a maioria das transições para a informalidade corresponde a passagens emprego para emprego, e uma minoria a transições desemprego para emprego. Eles estabelecem que a liberalização comercial desempenha um papel relativamente pequeno no aumento da informalidade, mas encontram evidências sugestivas de que várias dimensões da reforma constitucional, em particular, a regulamentação relativa a custos de demissão, horas extras, e poder sindical, explicam uma larga parte da informalidade.

Neri (2002) acha uma correlação negativa entre o grau de informalidade e a taxa de desemprego, o que poderia indicar o fato que o setor informal tem uma grande importância em absorver o excesso de mão-de-obra. Amadeo et al. (1994) também põem em evidência esse fato: na recessão do início dos anos 1990 o setor informal funcionou como uma importante fonte geradora de postos de trabalho, de fato durante este período aconteceu uma migração direta de trabalhadores do setor formal para o setor informal. O inverso também parece ser verdade, pois analisando a passagem entre empregos de ambos os setores, Neri (2002) mostra que a probabilidade de sair do setor informal para entrar no setor formal é maior em momentos de crescimento do que de recessão.

Ramos (2002) argumenta que a informalidade seria mais influenciada por um componente estrutural do que cíclico. O autor analisa os dados da Pesquisa Mensal de Emprego e nota mudanças na composição setorial da ocupação no mercado de trabalho urbano: uma expansão do setor de serviços é balançada pela diminuição da indústria de transformação. Tudo isso leva a um conseguinte crescimento da informalidade (Ulyssea, 2004). 
Para Ribeiro (2000) existem cinco principais fatores que influenciam a economia informal: a carga tributária, a intensidade de regulação, a transferências sociais, o mercado do trabalho e os serviços do setor público. As consequências das transferências sociais podem ser explicadas através de desincentivos para os indivíduos trabalharem na economia oficial: as transferências sociais somadas à renda do trabalho informal podem ser maiores que a renda do mercado formal. $\mathrm{O}$ autor também explica como as características do mercado do trabalho têm um papel importante: horários de trabalho reduzidos, ou pelo meio período e a aposentadoria precoce sugerem o fato que os indivíduos podem ter um segundo trabalho no setor informal.

Outro canal através do qual a informalidade pode diminuir é o favorecimento do empreendedorismo no setor formal. Spinola (2007) analisa no seu trabalho a Lei Geral da Micro e Pequena Empresa, em vigor no Brasil a partir de 2007, voltada especialmente ao segmento dos pequenos negócios para garantir ações de fomento a esses empreendimentos. $\mathrm{O}$ autor acredita que a Lei Geral da Micro e Pequena Empresa possa reforçar a contribuição das micro e pequenas empresas na redução da informalidade e o fortalecimento do tecido social e econômico por meio de desregulamentação, desoneração e estímulos. Enfim, o mesmo autor explica o círculo vicioso entre os serviços do setor públicos e a informalidade: a economia informal gera uma redução nos impostos recolhidos do estado, o qual reduz assim a qualidade e a quantidade dos serviços públicos. Uma pior infraestrutura pública e uma administração menos eficiente incentivam a entrada dos indivíduos na economia informal.

Ribeiro e Bugarin (2003) afirmam que há diversos fatores que explicam a informalidade no Brasil, porém tem forte evidência em dois aspectos. Primeiro, o crescimento econômico, considerado em termos nominais e reais, explica variações no mercado informal. Segundo, tanto o nível da tributação quanto o nível de regulação apresentam fortes indícios como fatores determinantes diretos do crescimento da economia informal.

\section{Especificações do modelo}

O objetivo desta análise empírica é tentar identificar fatores que têm uma correlação com a diminuição do trabalho informal no Brasil no período entre 2000 e 2010.

Os dados utilizados neste trabalho são o Censo, nas versões de 2000 e 2010, o Perfil dos Municípios Brasileiros de 2009, os dados da SEBRAE de 2009 (Serviço Brasileiro de Apoio às Micro e Pequenas Empresas) e do IBGE (Instituto Brasileiro de Geografia e Estatística).

Os dados do Censo são utilizados para calcular a variação na informalidade no Brasil no período 2000 e 2010. De fato, neste trabalho, a informalidade é considerada como a razão entre os trabalhadores sem carteira de trabalho assinada e o total de trabalhadores que compõem a população ativa. A escolha 
da característica "trabalho com ou sem carteira assinada" como determinante é dada pelo fato que a carteira assinada é uma garantia de que direitos fundamentais do trabalhador são respeitados, mesmo que a constituição garanta os direitos de qualquer indivíduo no exercício da sua função. Ademais, a presença de carteira de trabalho assinada é uma variável utilizada amplamente em estudos econômicos do governo e de várias instituições. De fato, a utilização do contrato de trabalho permite que as instituições públicas possam atuar com maior eficácia na redução das assimetrias no mercado de trabalho, pois consente uma mais eficiente relação entre oferta e demanda de emprego através um contato direto do Estado com os representantes sindicais, os empreendedores e os trabalhadores.

A pesquisa Perfil dos Municípios Brasileiros, em vez, foi usada por obter dummies sobre a presença em cada município de programas para incentivar o empreendedorismo formal, como isenções de impostos, ou programas para aumentar o nível de educação e diminuir a evasão escolar. Por outro lado, os dados da SEBRAE serviram para individuar os municípios que aprovaram a Lei Geral da Micro e Pequena Empresa. Enfim os dados do IBGE foram utilizados para calcular as variações do Produto Interno Bruto em cada município brasileiro no período 1999 - 2009.

O estudo empírico analisa vários possíveis fatores considerando os dados ao nível dos municípios brasileiros. Os possíveis fatores que a análise tem em consideração são aqueles que surgem da teoria econômica:

1. Mudanças na regulação estatal e na tributação;

2. Crescimento econômico;

3. Nível de escolaridade dos indivíduos que entram no mercado do trabalho;

4. Mudanças estruturais.

A análise desenvolvida por esta pesquisa sobre a redução do trabalho informal no Brasil considera como variáveis do primeiro grupo: a implantação da "regulamentação da lei geral sobre as micro e pequena empresas" nos municípios ( $L G)$ a "Isenção total do IPTU” (IPTU) e a "Cessão de terrenos" (CT) em favor de empreendedores.

A Lei Geral das Micro e Pequenas Empresas (123/06) foi sancionada em dezembro de 2006. A lei regulariza e amplia, em boa parte dos casos, as vantagens da maioria das micro e pequenas empresas (MPEs) através a criação de uma série de facilidades tributárias, de negócios e redução da burocracia. A lei precisa ser implementada em cada município brasileiro; é próprio a presença no município desta implementação que este trabalho vai considerar como proxy de um fator do primeiro grupo. A variável “implantação da regulamentação da lei geral sobre as micro e pequena empresas" então é qualitativa e por isso implica a necessidade de construção de uma variável dummy, a qual tem valor igual a um, se a Lei foi regulamentada depois de 2010 no município, e zero, caso contrário. 
A isenção do IPTU é incluída na nossa análise porque pode pertencer à segunda tipologia de políticas públicas sugeridas para combater a informalidade em Tokman (2008). Uma primeira dimensão é ligada à redução da pobreza. Em vez, a segunda dimensão está em relação com o suporto social e o bem-estar e tem como foco a incorporação do setor informal no processo de modernização. Essas políticas incorporam as inter-relações entre as pequenas unidades de produção e as famílias envolvidas. As casas das famílias têm um duplo papel para as famílias pobres: são uma moradia, mas também o lugar de produção e dos negócios. Políticas em favor da aquisição, mas também da manutenção da propriedade das casas por parte das famílias, por exemplo, através uma redução dos impostos sobre elas, asseguram a integridade das famílias e a facilidade de negócios.

Como elemento da segunda categoria a análise empírica inclui somente a "Variação PIB" em cada município no período de tempo 1999 - 2009 (PIB).

Passando ao terceiro grupo, são tidas em consideração algumas variáveis que podem explicar uma melhoria no nível de escolaridade da população de cada município. As variáveis em questão são qualitativas e ligadas à presença no município de ações para a "Diminuição da evasão escolar" (DEE), para as "Melhorias ou implementação de programas de assistência escolar" (PAE), para a "Melhoria do transporte dos alunos" (TA) e para a "Instituição de cursos de educação profíssional" (EP). Estas variáveis são utilizadas através a construção de uma variável dummy, a qual tem valor igual a um se a ação em questão é presente no município e zero caso contrário.

Enfim, no quarto grupo, consideramos a mudança estrutural, ou seja, quanto em cada município os setores da agricultura, da indústria e dos serviços mudaram no período que temos em consideração. Para fazer isso, são calculadas as variações no período 2000-2009 de quanto em proporção cada setor participa na formação do PIB em cada município. Porém no modelo colocamos somente o setor dos serviços (SERV), de modo a evitarmos a presença de multicolinearidade.

O modelo pode ser sintetizado através a seguinte equação:

$\Delta I_{i}=\beta_{0}+\beta_{1} L G_{i}+\beta_{2} I P T U_{i}+\beta_{3} C T_{i}+\beta_{4} P I B+\beta_{5} D E E_{i}+\beta_{6} P A E_{i}+\beta_{7} T A_{i}+\beta_{8} E P_{i}++\beta_{9} S E R V_{i}$ $+\mu_{i} \quad$ i: iésimo município

Tendo como referência o que a teoria explica sobre o assunto podemos supor que as todas as variáveis explicativas vão ter um efeito negativo sobre a informalidade (I), com exceção de SERV. Por exemplo, é coreto assumir que a presença (no caso de dummy) ou o crescimento da maioria das variáveis (com exceção de SERV) vai diminuir a informalidade no município, com coeficientes estimados então negativos, em vez o crescimento da proporção do setor dos serviços vai aumenta-la. 


\section{Analise dos resultados da regressão}

Os resultados da regressão usando a metodologia dos mínimos quadrados ordinários podem ser vistos na tabela 4.

\section{Tabela 4. Resultados}

\begin{tabular}{ll}
\hline & Coeficientes \\
\hline Intercepto & $0,10^{* *}$ \\
LG & $-0,08^{* *}$ \\
IPTU & $-0,09 * *$ \\
CT & $-0,06$ \\
PIB & 0,00 \\
DEE & $-0,10^{* * *}$ \\
PAE & $-0,07 * *$ \\
TA & $-0,08^{* * *}$ \\
EP & $-0,11$ \\
SERV & $0,57 * * *$ \\
\hline
\end{tabular}

Fonte: Próprio autor.

Nível de significância : *10\%, **5\%, ***1\%

Os resultados da análise empírica mostram que alguns fatores colocados como hipótese da recente queda da informalidade têm relevância empírica.

A regulamentação da Lei Geral das MPEs, considerando um nível de significância de 5\%, tem relevância estatística e também um efeito negativo como previsto pela teoria.

A "Isenção total do IPTU", que pode ser vista como uma proxy da redução dos impostos, tem relevância estatística, a um nível de significância de 5\%. Ainda mais, a relação é negativa: nos municípios em que foi aprovada uma isenção total do IPTU para promover o empreendedorismo, a informalidade teve uma variação negativa.

A sucessiva variável que assumimos ter uma correlação importante com a taxa de informalidade é a cessão de terrenos. Contudo podemos ver que a relação entre esta variável e a informalidade não é significativa estatisticamente.

Passando a considerar a única variável incluída no grupo sucessivo, que seria o crescimento econômico entre 1999-2009 podemos afirmar que não tem correlação entre variação do PIB e mudanças no trabalho informal neste período.

Mello e Santos (2009) dizem que o comportamento anticíclico das taxas de informalidade pode ter sentido somente no curto prazo, em vez no longo prazo a variação do PIB perde força para explicar crescimento ou queda no trabalho informal. Para justificar tendências mais longas de redução do 
trabalho informal como as observadas a partir de 2000, o crescimento econômico não tem muita relevância, porque é razoável supor que no longo prazo tanto os níveis de emprego quanto os de salário se aproximem dos níveis de equilíbrio. Então no longo prazo o crescimento do PIB não gera uma demanda de trabalho superior da oferta no mercado do trabalho formal e assim a passagem de indivíduos do mercado informal para aquele formal não acontece (Mello, Santos, 2009).

Países com um setor informal importante no complexo econômico, como acontece no Brasil, desenvolvem ciclos econômicos mais voláteis, causados pela interconexão que existe entre os setores formal e informal.

Por exemplo, Bajada (2003) na pesquisa dele sobre a Austrália, chegou à conclusão que choques negativos sobre a economia formal têm impactos maiores sobre a economia informal do que choques positivos do mesmo tamanho.

O estudo de Schneider e Enste (2000) confirma quanto explicado e também adiciona o fato que o setor informal e formal são ligados em países como o Brasil. Os autores põem em evidencia o fato que mais de $66 \%$ da renda do setor informal é passada ao formal através gastos neste setor; acontece assim que uma redução da renda produzida no setor informal diminui a demanda por produtos e serviços da economia formal.

No caso do Brasil, a presença de um grande setor informal leva a flutuações na atividade econômica. Um setor informal maior em tamanho de $10 \%$ em um país respeito um outro implica uma maior volatilidade de $16,1 \%$ do PIB, de 5,3\% do investimento e de 6,1\% do consumo (Ferreira Tiryaki, 2008).

Os resultados das análises de regressão apresentados no trabalho de Ferreira Tiryaki (2008) respeitam essa hipótese: a dimensão do setor informal possui uma correlação positiva com a volatilidade dos índices da economia.

Podemos também apresentar os dados da segunda edição do Índice de Economia Subterrânea, da FGV (Fundação Getulio Vargas) e do Etco (Instituto Brasileiro de Ética Concorrencial). Fernando de Holanda Barbosa Filho, desenvolvendo este Índice, demonstra que a expansão da geração de empregos formais, gerado por exemplo através o crescimento econômico, não diminui o crescimento da economia informal. Segundo o autor, o contrário de quanto esperado acontece porque as economias formal e informal se influenciam reciprocamente. Quando um setor aumenta a própria renda, vai estimular a compra de bens e serviços no outro setor e vice-versa. A explicação também inclui a modalidade através da qual o mercado de trabalho tem o seu papel. Como a maioria dos economistas pensa, a expansão da economia formal absorve trabalhadores informais, mas a economia informal continua do mesmo tamanho ou cresce. De fato, a aceleração do consumo dos novos 
trabalhadores formais impulsiona a economia subterrânea, devido ao fato que estes consumidores gastam uma grande porção da renda em bens e serviços informais (Barbosa Filho, De Moura, 2012). Passando ao sucessivo grupo e, portanto, à sucessiva variável, podemos observar que a Diminuição da evasão escolar tem uma forte e, sobretudo, negativa correlação com a variação do trabalho informal.

O problema que surge neste campo é a dificuldade em distinguir entre a causa e o efeito. Em geral, não conseguimos saber se uma melhoria nos níveis de evasão escolar faz diminuir o trabalho informal, ou se uma menor presença da informalidade, sobretudo como trabalho precoce, devida a outras causas, consegue diminuir a evasão escolar.

A falta de interesse pela escola por parte dos alunos é considerada a primeira causa de evasão escolar no Brasil. A pesquisa “Motivos da Evasão Escolar" desenvolvida pela Fundação Getúlio Vargas, demonstra que $40 \%$ dos jovens de 15 a 17 anos não continuam o ensino por falta de interesse em estudar. A segunda causa de evasão escolar individuada foi a necessidade de trabalhar, que é causa de $27 \%$ do afastamento das escolas, e a dificuldade de acesso escolar com uma percentagem de 10,9\% (Nogueria Torres, 2010).

Considerando essas percentagens podemos supor que no Brasil pode existir principalmente uma relação em que a evasão escolar é a causa e o trabalho informal é o efeito. De fato, somando a percentual do motivo "falta de interesse pela escola" e "dificuldade de acesso à escola" conseguimos a percentual de 50,9 , maioria absoluta e valor bem superior a $27 \%$ do motivo "necessidade de trabalhar".

Estes dados nos levam também a observar as sucessivas variáveis desse trabalho: "Melhoria ou implementação de programas de assistência escolar" e "Melhoria do transporte dos alunos". As duas variáveis têm efeito negativo, como esperado, e podem ser consideradas significativas estatisticamente, ao $5 \%$ e $1 \%$ respectivamente. De fato, as duas variáveis confirmam ulteriormente os efeitos positivos dos investimentos na educação. As variáveis têm também efeitos negativos sobre a informalidade e assim estão de acordo com o esperado.

Para analisar mais em detalhe os efeitos do nível educacional sobre a informalidade, a tabela 5 mostra a porção de trabalhadores informais em cada nível educacional.

O fato que surge estudando esta tabela é que em cada grupo a percentagem de trabalhadores informais não diminui amplamente no período entre 2001 e 2009: a maior queda (2,78 pontos percentuais) acontece no nível escolar de "15 anos ou mais", a qual não pode ser considerada uma grande diminuição; no nível "8 a 10 anos" tem até um crescimento do trabalho informal. Esse resultado implica que as mudanças na composição dos grupos de escolaridade são fundamentais para explicar a queda que observamos no nível de informalidade agregada. Com o aumento no nível de 
escolaridade, muitos indivíduos passaram do grupo de pessoas com pouca escolaridade e elevado grau de informalidade para o grupo de trabalhadores mais escolarizados e com baixo grau de informalidade (Reis, 2012).

Tabela 5. Porção de trabalhadores informais por anos de estudo (\%)

\begin{tabular}{|l|l|l|l|l|l|l|l|l|l|}
\hline & 2001 & 2002 & 2003 & 2004 & 2005 & 2006 & 2007 & 2008 & 2009 \\
\hline Menos de 1 ano & 83,01 & 83,78 & 83,49 & 83,47 & 83,79 & 83,69 & 82,34 & 81,3 & 81,39 \\
\hline 1 a 3 anos & & & & & & & & & \\
& 77,02 & 77,13 & 76,73 & 77,23 & 77,32 & 76,68 & 76,65 & 75,89 & 75,24 \\
\hline 4 a 7 anos & 66,25 & 67,44 & 67,39 & 67,73 & 67,98 & 67,79 & 67,14 & 65,36 & 65,81 \\
\hline 8 a 10 anos & 51,6 & 54,16 & 55,35 & 55,5 & 55,42 & 55,87 & 55,59 & 54,44 & 54,77 \\
\hline 11 a 14 anos & & & & & & & & & \\
& 35,37 & 36,13 & 35,72 & 35,93 & 35,7 & 35,4 & 35,27 & 33,99 & 34,31 \\
\hline 15 anos ou mais & 27,67 & 26,64 & 26,75 & 26,71 & 27,31 & 26,19 & 26,22 & 25,49 & 24,89 \\
\hline
\end{tabular}

Fonte: IPEA,2011

Passando a discutir as sucessivas variáveis, podemos ver que "Instituição de cursos de educação profissional" não tem alguma significância estatística para explicar a variação do trabalho informal. Enfim, em relação ao último grupo de variáveis, o seja, mudança estrutural, podemos dizer que a variável que descreve variações da proporção do "setor serviços" na formação do PIB tem relevância estatística. Temos que adicionar que neste caso o nível de significância é de $1 \%$ e que também o coeficiente é positivo, não podendo assim rejeitar a teoria que descreve um setor dos serviços ligado positivamente à informalidade.

\section{Conclusões}

O presente trabalho teve o objetivo de analisar algumas hipóteses sobre a recente diminuição da informalidade no Brasil.

Primeiramente, podemos concluir que variáveis ligadas ao grupo "nível de escolaridade dos indivíduos que entram no mercado do trabalho" são aquelas que aparecem ser mais correlacionadas com o fenômeno aqui estudado. De fato, nos municípios brasileiros onde tem ações para promover o acesso ou o a permanência na escola, a informalidade diminuiu em forma mais vigorosa.

Em segundo lugar, nesta pesquisa, o crescimento econômico não resulta ser uma possível causa importante que explica a queda da informalidade na recente década. 
Em terceiro lugar, "mudanças na regulação estatal e na tributação" aparecem ser também significativas, na maioria dos casos, no explicar o fenômeno. O melhor resultado é oferecido pela variável Lei geral da Micro e Pequena Empresa regulamentada, fato que indica como a burocracia impede a entrada das empresas e dos indivíduos no setor formal.

Enfim, a categoria de variáveis ligadas à mudança estrutural aparece explicar a queda na informalidade, considerado que existe uma correlação significativa da única variável analisada com a informalidade.

Em geral, a conclusão deste trabalho está em sintonia com quanto descrito em Tokman (2008) sobre a identificação do mercado do trabalho informal. O trabalho informal pode ser identificado principalmente através as suas características de "maneiras de fazer as coisas". Estas características são completamente o oposto de aquelas do setor formal: facilidade na entrada de novos agentes, utilização de recursos locais, propriedade e gestão dos negócios ao nível familiar, pequena escala de produção, utilização em maior proporção de trabalho em vez que de capital, capacidades e conhecimentos adquiridos fora do sistema formal de educação (Tokman, 2008).

Então, para reduzir a informalidade precisamos que o mercado de trabalho informal consiga superar essas características. A educação é o meio pelo qual um país consegue mudar a parte da estrutura produtiva e dos serviços que tem tais características. 


\section{Referências bibliográficas}

AMADEO, E.; BARROS, R.P.; CAMARGO, J.M.; GONZAGA, G.; MENDONÇA, R. A natureza e o funcionamento do mercado de trabalho brasileiro desde 1980. IPEA, Série Seminários, 1994

BAJADA, C. Business cycle properties of the legitimate and underground economy in Australia. The Economic Record, v. 79, p. 397-411, 2003

BARBOSA FILHO, F. H., DE MOURA, R. L. Evolução Recente da Informalidade no Brasil: Uma Análise Segundo Características da Oferta e Demanda de Trabalho, Instituto brasileiro de economia, FGV, 2012

BARROS, R. P. de; CORSEUIL, C. The impact of regulations on Brazilian labor market performance. IADB ,Discussion Paper, R-427, 2001

BOSH, M.; GONI, E.; MALONEY, W. The determinants of rising informality in Brazil: evidence from gross worker flows. IZA, Discussion Paper, n. 2.970, 2007

CARNEIRO, F. G. The changing informal labour market in Brazil: cyclicality versus excessive intervention. LABOUR - Review of Labour Economics and Industrial Relations, Itália, v. 11, n. 1, p. 3-22, 1997

FERREIRA TIRYAKI, G. A informalidade e as flutuações na atividade econômica, Estudos Econômicos, vol.38 no.1 São Paulo Jan./Mar. 2008

INSTITUTO DE PESQUISA ECONOMICA APLICADA (IPEA), Características da formalização do mercado de trabalho brasileiro entre 2001 e 2009, Brasília, 2011

KASSOUF A.L.;NUNES de ALMEIDA A.; PONTILI R. M.; RODRIGUES F. A. Análise das políticas e programas sociais no Brasil, Brasília, OIT / Programa IPEC América do Sul, 108, 2004

MELLO R.F.; SANTOS D.D. Aceleração educacional e a queda recente da informalidade. IPEA, Boletim Mercado de Trabalho 39, 2009 
NERI, M.C. Decent Work and the Informal Sector in Brazil. EPGE, Ensaios Econômicos, n.461, 2002

NERI M.C. Informalidade. In: Tafner P, Giambiagi F, organizadores. Previdência no Brasil: debates, dilemas e escolhas. Rio de Janeiro: Ipea; p. 285-319, 2007

NOGUEIRA TORRES, M.C. Direito à educação: a evasão escolar causada pelo trabalho infantil, Fundação Escola do Ministério Publico do Estado do Paraná, 2010

REIS, M. Um panorama do mercado de trabalho brasileiro no período 1996-2009, Mercado de trabalho conjuntura e análise, IPEA, 2012

RIBEIRO, R.N. Causas, efeitos e comportamento da economia informal no Brasil. Universidade de Brasília. Departamento de Economia. Mestrado em Economia do Setor Público. Dezembro, 2000. (Dissertação de Mestrado)

RIBEIRO R; BUGARIN, M.N.S. Fatores determinantes e evolução da economia submersa no Brasil. Estudos Econômicos vol.33 no.3, São Paulo July/Sept, 2003

SCHNEIDER, F, ENSTE, D, H, Shadow Economies: Size, Causes, and Consequences, Journal of Economic Literature, American Economic Association, vol. 38(1), pages 77-114, March, 2000

SOARES, F.V. Do Informal Workers Queue for Formal Jobs in Brazil?. IPEA, texto para discussão, n. 1021, Brasília, 2004

SPINOLA, A. S. Os Pequenos Negócios, a Informalidade e suas Perspectivas. Revista SEBRAE, edição número 20, janeiro / fevereiro, 2007

TOKMAN, V. The informal sector. in: Dutt, A. and Ros, J. (Eds) International Handbook of Development Economics. Vol. 1, pag. 483-495, 2008

ULYSSEA, G. L. Instituições e a Informalidade no Mercado de Trabalho Brasileiro. PUC-Rio, 2004

ULYSSEA, G. L. Informalidade no mercado de trabalho brasileiro: uma resenha da literatura, Revista de Economia Política, vol. 26, nº 4 (104), pp. 596-618, 2006 